\title{
Comparative analysis of lead and cadmium levels in various brands of canned and processed meat products in Lebanon
}

\author{
P. J. Obeid, C. Saliba, M. Younis, S. Aouad \& J. El-Nakat \\ Department of Chemistry, Faculty of Sciences, \\ University of Balamand, Lebanon
}

\begin{abstract}
Knowledge of toxic metal concentrations in meat products is important for assessing their risk on health when consumed. Levels of such metals have neither been questioned, nor the appropriate total dietary studies (TDS) have ever been conducted in Lebanon to carry out proper risk assessments. The study reports on the levels of lead $(\mathrm{Pb})$ and cadmium $(\mathrm{Cd})$ in canned and processed meats sold in the north. 75 brands of canned and 33 of processed meats were purchased from local markets. Digested samples were analysed using graphite furnace atomic absorption spectroscopy (GFAAS) to determine the metals' concentrations. All samples were analysed in triplicate and included blanks and certified reference material (CRM) to validate the analysis. 46 samples (61\%) of the canned showed levels of $\mathrm{Pb}$ ranging from 0.2 to $816.1 \mu \mathrm{g} / \mathrm{kg}$ while 68 samples (91\%) showed $\mathrm{Cd}$ levels ranging from 0.19 to $138.3 \mu \mathrm{g} / \mathrm{kg}$. For the processed, $91 \%$ of the samples revealed $\mathrm{Pb}$ levels ranging from 0.245 to $61.3 \mu \mathrm{g} / \mathrm{kg}$, while $97 \%$ tested positive for the presence of $\mathrm{Cd}$ in the range of 0.02 to $29.7 \mu \mathrm{g} / \mathrm{kg}$. In general, processed meats were found to have lower concentrations of both metals, whereas canned meats posed the greater risk. In comparison with the provisional tolerable weekly intake levels (PTWI), data showed that adults almost reached the set PTWIs for a number of samples, whereas children, have markedly exceeded such values, sometimes by $186 \%$. Data suggests that immediate action should be taken to carry out comprehensive TDS and risk assessment studies.

Keywords: lead, cadmium, canned meat, processed meat, health hazard, microwave acid-assisted digestion, GFAAS.
\end{abstract}




\section{Introduction}

The toxicity of heavy metals from food sources has been well documented over the past years in the literature [1-6]. Moreover, environmental pollution is gradually becoming an immense concern globally, and accordingly, food chain contamination is becoming ever more important in light of its role in human health and nutrition. There exist a number of environmental pollutants which constitute a potential danger to human beings [7, 8]. Sources of contamination with the rise of industries, burning of fuel, coal, and mining, all contribute to increase the body burden of such toxic elements. Even worse, everything around us from polluted air, contaminated drinking water, and accumulated toxins in foodstuffs will eventually contribute to our daily intake of specific toxins. Metals such as $\mathrm{Pb}$ and $\mathrm{Cd}$ have been shown to cause many adverse health effects in humans [9, 10]. Excess lead contamination for example, can cause serious damage to the brain, kidneys, nervous system, and red blood cells. Young children and infants are particularly vulnerable to lead poisoning. Moreover, lead has the ability to bio-accumulate in plants and animals. Its concentration is generally magnified in the food chain [11]. Cadmium, a human carcinogen [12] has a long residence time in human tissues (10-40 years), especially in the kidneys $[13,14]$. For these reasons, it is of most importance to monitor the lead and cadmium content as well as other metals in dietary intakes.

Worldwide, meat is considered an important food category, being composed of mostly proteins, fat and various essential elements, is vital for growth and preservation of good health [15]. On the other hand, contamination is transferred to animals and to humans through direct exposure, polluted water and crops as well as industrial effluents and other activities [16, 17]. Other possible contamination sources of meat could arise from slaughter houses or even through transportation, processing or canning. In the developed countries (USA, Canada, EU countries, and others), numerous studies have targeted the quantification of $\mathrm{Pb}$ and $\mathrm{Cd}$ in meats and their products [17-23]. In addition to such studies, others [1-4] have utilized TDSs as suggested by health organizations, to assess the risk from consuming such products.

Due to the absence of the appropriate controls and frequent screening of meat products in Lebanon, and due to the lack of studies and research in the area, it becomes crucially important to determine the levels of such toxic elements in various meat tissues for the purpose of finding out whether the Lebanese individuals are exposed to high levels of such metals or not from consuming such products. Only one study have been made in Lebanon by Nasreddine et al. [3] which addressed dietary exposure to toxic metals ( $\mathrm{Pb}, \mathrm{Cd}$ ) utilizing the TDS approach in an adult Lebanese urban population in Beirut in which toxic metals were analyzed in sample aliquots of cooked meals. The data suggested that $3.2 \%$ of the PTWI of Pb (25 $\mu \mathrm{g} / \mathrm{kg}$ bw) have been reached, while $21.7 \%$ of the PTWI of Cd (7 $\mu \mathrm{g} / \mathrm{kg}$ bw) have been reached. One of the major drawbacks of such study however, is the use of consumption data referring to urban population living in Beirut only which does not accommodate other urban or rural areas. Different areas in the country may prepare or use their edibles in 
different ways. In addition, many individuals and families are not economically and financially stable and do not have the possibility of preparing foods as suggested by the TDS approach. More important, the study did not include any of the canned and processed meats. A category of products that can be consumed without any preparation or cooking and is widely available on the go.

Accordingly, the focus of this study was first to determine the $\mathrm{Pb}$ and $\mathrm{Cd}$ levels of available canned and processed meats sold in local markets; second, to check whether such levels are above or below the maximum allowed values; third, to compare the analyzed levels with other internationally reported values; fourth, to estimate the intake of $\mathrm{Pb}$ and $\mathrm{Cd}$ when such products are consumed, and finally to raise the awareness of individuals should there be any alarming levels from exposure to such toxic metals. In our views, such study may serve as an alarm for researchers, whether in the governmental or private sectors in the area, to become engaged in this research so as to create a healthier environment.

\section{Materials and methods}

\subsection{Reagents and glassware}

Prior to any application, all plastic and glass-wares used throughout the study were washed with soap and tap water, rinsed with $\mathrm{ddH}_{2} \mathrm{O}$ (Milli-Q system (Millipore, Numelab), and then soaked overnight in $10 \%$ nitric acid solution. Prior to usage, any item was washed three times with $\mathrm{ddH}_{2} \mathrm{O}[5,6$, 9]. Aciddigested samples were stored in 50-mL polypropylene conical tubes (LaboTech, Lebanon), which were soaked in $10 \%$ nitric acid solutions, and washed with $\mathrm{ddH}_{2} \mathrm{O}$ prior to use. Reagents and sample cups (LaboTech, Lebanon) were also soaked and washed thoroughly with $\mathrm{ddH}_{2} \mathrm{O}$ before filling them with the samples to be analyzed. Working standards for lead and cadmium were prepared using standard solutions supplied by Romil-Pure chemistry (Standard solutions $1000 \mathrm{ppm}$ element reference solution). Diluted solutions of a high quality and purity 65\% concentrated nitric acid were used for the sample digestion as well as for the preparation of wash solution and diluents for the Graphite Furnace Atomic Absorption Spectrometer (GFAAS) [5]. Ascorbic acid 99.99\% pure and trace metal basis (purchased from Sigma-Aldrich) used as pure chemical matrix modifier for lead detection, while magnesium nitrate $99.99 \%$ pure and trace metal basis (purchased from Sigma-Aldrich) used as pure chemical matrix modifier for cadmium detection in the GFAAS. Certified Reference Material (CRM) (SRM1577C Bovine Liver NIST National Institute of Standards and Technology) were used to validate the analytical procedure utilized.

\subsection{Samples and sample treatment}

Canned and processed meat (cold cuts) samples were purchased from various supermarkets in North Lebanon. 75 brands of canned meat and 33 different types of processed meat were purchased and analyzed. Canned meat samples whether locally produced or imported consisted of the following groups: chicken, beef, 
mixed, pork, and duck. The groups have included hotdogs, luncheon meat, corned beef, pate, etc. similarly, the processed ones were divided in the following groups: turkey, pork, mixed chicken-turkey, mixed chicken-beef, mixed pork-chicken, and mixed pork-beef. Such groups have included the cold cuts or sliced mortadella, ham, salami, pepperoni, etc. For each collected sample, whether canned or processed, few grams of tissues were taken from separate subsamples of the same brand, pooled together and homogenized by cutting them into very small pieces. The homogenates were dried in a programmable oven (Venticell, W.P.Katul) at $70^{\circ} \mathrm{C}$ overnight until a constant sample weight was obtained [2, 5, 6]. After drying, $0.5 \mathrm{~g}$ of each sample was weighed and transferred to a Teflon reaction vessel specific for the Ethos 1 microwave digestion oven (Milestone Ethos 1 Labstation) followed by the addition of $7 \mathrm{~mL}$ of purified concentrated nitric acid (65\%), and $1 \mathrm{~mL}$ of $30 \%$ concentrated hydrogen peroxide $[3,5,6]$. Similarly, and for quality control purposes, $0.5 \mathrm{~g}$ of the certified reference material (CRM) was also included in each batch and treated in the same manner as any other sample. After addition of the acids, the vessels were left under a fume extraction hood for at least 15 minutes to allow the formed gases to escape. The vessels were, then, sealed and placed inside the microwave oven and digested using a three-step program. During the first step, samples were heated from room temperature to $200^{\circ} \mathrm{C}$ in $30 \mathrm{~min}$ at 1000 watts. The second step consisted of maintaining the samples at $200^{\circ} \mathrm{C}$ for $30 \mathrm{~min}$ at 1000 watts. In the final step, samples were brought to room temperature. Digested samples $(\sim 7 \mathrm{ml})$ were transferred into $25 \mathrm{~mL}$ volumetric flasks and were diluted with $\mathrm{ddH}_{2} \mathrm{O}$ up to the mark prior to their transfer to $50 \mathrm{~mL}$ polypropylene tubes in which they were stored in the refrigerator before analysis with GFAAS.

For trace metal analysis, a Thermo-Electron $\mathrm{M}$ series graphite furnace atomic absorption spectrometer (GFAAS) equipped with deuterium and Zeeman background correction (Zeeman Furnace GF95Z) together with an Autosampler (FS95) was used. The sample atomization is carried out in specialized graphite tubes (Thermo Elemental Omega Platform Extended Lifetime Cuvettes). Coded hollow cathode lamps of lead and cadmium (Thermo-electron Corporation, Germany) were included in the GFAAS's carousel, where the lamp selection was done automatically based on the metal to be analyzed [5]. During all stages of $\mathrm{Pb}$ and Cd analysis, 99.999\% pure argon gas (supplied by Chehab Industrial and Medical Gases SAL, Lebanon) was used as an internal inert gas having a flow of $300 \mathrm{~mL} / \mathrm{min}$.

\subsection{Sample analysis by GFAAS}

The optimized parameters for $\mathrm{Pb}$ and $\mathrm{Cd}$ were entered into the software of the GFAAS. Calibration standards were carefully prepared by simultaneous dilution of the stock solutions, starting from 1000ppm down to 10ppb (mother solution) for lead standards and 1ppb (mother solution) for cadmium standards, by using 10 fold dilutions each time, as to diminish the analytical preparation errors as much as possible. The mother solutions were used by the GFAAS's auto-sampler in order to create automatically a specified calibration curve specific for each 
metal. The number of calibration points was already set by the instrument and included 5 points. $0.5 \%$ nitric acid solution was used by the auto-sampler to make the needed dilutions, while $1 \%$ nitric acid solution was used to wash the auto-sampler injection tube between each dilution so as to prevent any cross-over contamination between the calibration points [5].

Aliquots of approximately $1 \mathrm{~mL}$ of each digested sample as well as digested CRMs were placed in a 1-mL polypropylene sample cups and were arranged into the auto-sampler according to an auto-sampler guide generated automatically by the software. Standard mother solution, diluents, as well as the matrix modifiers were placed in $20 \mathrm{~mL}$ polypropylene reagent cups, and loaded into the autosampler according to the same auto-sampler guide [5].

The total analysis, starting from calibration curve preparation ending up with the sample analysis was programmed to be carried out without any human interference thus decreasing contamination sources [5]. With the purpose of eliminating any possible contamination, the auto-sampler washes itself after each run with $0.1 \%$ nitric acid solution.

The auto-sampler can perform up to sixty samples injections in addition to all the necessary dilutions and preparations, in one run, thus ensuring high quality control of analysis. On the other hand, all specimens were run in batches with digested blanks and digested CRMs. Digestion blanks were used to test for the presence of any possible contamination throughout the whole procedure [6]. Furthermore, all samples were analyzed in triplicates, where a mean value is calculated. For further quality control, the instrument was programmed to periodically re-measure sample blanks and standards from the calibration curve every 10 samples to check for any instrumental variations during the analysis, thus ensuring fidelity and consistency of the data. Moreover, and for investigating the recovery of the whole procedure, every batch included a sample of certified reference material so as to ensure that the method used was accurate and that the produced results are genuine. In this case, all our CRM samples had recovery values that ranged within the acceptable analytical range of $80-120 \%$.

\section{Results and discussion}

Due to highly important reasons discussed earlier, and since such products were never tested before in this country, and because the only TDS [3] study done does not include such products, it becomes a necessity to carry out this study. The analyzed samples in this study, their place of origin, and their mean concentrations of lead and cadmium are summarized in tables 1 and 2 .

The levels of $\mathrm{Pb}$ and $\mathrm{Cd}$ whether in canned or processed meat products extended over a wide range of concentrations (tables 1 and 2). This strongly suggested that $\mathrm{Pb}$ and $\mathrm{Cd}$ contamination was not only due to a constant factor such as processing and/or canning, but rather to many other factors which may include type of meat, its origin, and diet of the corresponding animal during the bringing up process. In table 1, 46 samples (61\%) of the canned meat showed levels of $\mathrm{Pb}$ ranging from 0.2 to $816.1 \mu \mathrm{g} / \mathrm{kg}$, whereas 68 samples (91\%) showed Cd levels ranging from 0.19 to $138.3 \mu \mathrm{g} / \mathrm{kg}$. 
Table 1: $\quad$ Lead and cadmium concentrations analyzed in canned meat brands. In the main text, sample brands are referred to by using their sample codes. Values are reported as mean concentrations in $\mu \mathrm{g} / \mathrm{kg}$ based on dry weight basis.

\begin{tabular}{|c|c|c|c|c|}
\hline $\begin{array}{l}\begin{array}{l}\text { Sample } \\
\text { code }\end{array} \\
\end{array}$ & Brand Name & $\begin{array}{c}\text { Place of } \\
\text { Origin }\end{array}$ & $\begin{array}{c}P b \\
(\mu \mathrm{g} / \mathrm{kg})\end{array}$ & $\begin{array}{c}\text { Cd } \\
(\mu \mathrm{g} / \mathrm{kg})\end{array}$ \\
\hline B1 & Maxim's Corned Beef & Brazil & nd & nd \\
\hline B2 & Food Love & Brazil & nd & 75.76 \\
\hline B3 & Zwan Beef & Holland & nd & 38.87 \\
\hline B4 & Zwan Beef Hot \& Spicy & Holland & nd & 20.35 \\
\hline B5 & Bordon & Brazil & nd & nd \\
\hline B6 & Del Monte Beef Luncheon Meat & Jordan & nd & 21.86 \\
\hline B7 & Target Corned Beef & Holland & nd & 2.41 \\
\hline B8 & Niers Saussages & Holland & nd & 0.65 \\
\hline B9 & Target Corned Beef Low Fat & Holland & nd & 0.82 \\
\hline B10 & Al Maraai Jordonia & Jordan & nd & 65.75 \\
\hline B11 & Maxim's Frankfurter Beef & Brazil & 0.3 & nd \\
\hline B12 & Sara Luncheon Meat & Brazil & 1.2 & 4.15 \\
\hline B13 & Maxim’s Corned Beef Black & Brazil & 2.7 & 0.43 \\
\hline B14 & Zwan Beef Hot Dog In Glass & Holland & 3.4 & 3.8 \\
\hline B15 & Groot & & 3.8 & 6.87 \\
\hline B16 & Maxim’s Beef Pate & Brazil & 4.2 & 4.13 \\
\hline B17 & Poppenburger frankfurters Beef & Germany & 7.7 & 3.48 \\
\hline B18 & Deli Beef & Jordan & 9.4 & 9.79 \\
\hline B19 & Bocklunder Beef Bockwurst & Germany & 13.2 & 0.19 \\
\hline $\mathrm{B} 20$ & Maxim’s Frankfurter & Brazil & 15.3 & 4.71 \\
\hline B21 & Maxim's Beef Luncheon Meat & Brazil & 17.7 & 1.96 \\
\hline $\mathrm{B} 22$ & Niers Beef & Holland & 25.5 & 28.21 \\
\hline $\mathrm{B} 23$ & Poppenburger USA Pure Beef & Germany & 23.9 & 1.2 \\
\hline $\mathrm{B} 24$ & Food Love Hot Dog & Brazil & 55.3 & 89.27 \\
\hline $\mathrm{B} 25$ & Maxim’s Beef Hot Dog & Brazil & 60.4 & 7.94 \\
\hline P1 & Niers Bockwurst & Holland & nd & nd \\
\hline $\mathrm{P} 2$ & Poppenburger USA Style & Germany & nd & nd \\
\hline P3 & Tulipe Pork Hot Dog & Denmark & nd & 19.66 \\
\hline P4 & Tulipe Liver Pate & Denmark & nd & 74.53 \\
\hline P5 & Poppenburger USA & Germany & nd & 7.27 \\
\hline P6 & Maxim's Frankfurters & Germany & 1.2 & 0.41 \\
\hline P7 & TEDDY & China & 2 & 9.89 \\
\hline P8 & La Piarra Frankfurt & Spain & 2.2 & 5.78 \\
\hline P9 & PoppenburgerBockwurst (Green) & Germany & 6.4 & 1.8 \\
\hline $\mathrm{P} 10$ & La Piara Pate La Pimenta & Spain & 9.6 & 3.52 \\
\hline P11 & Poppenburger Bockwurst (Red) & Germany & 17.5 & 2.93 \\
\hline P12 & Maling Scof Pork & China & 28 & 5.83 \\
\hline $\mathrm{P} 13$ & Maxim’s Pork Hot Dog & Brazil & 76.5 & 138.3 \\
\hline $\mathrm{P} 14$ & Epicure Pate & Belgium & 413.9 & 30.71 \\
\hline M1 & Maxim’s Duck Pate & Brazil & nd & 4.98 \\
\hline M2 & Al Mouna Beef Hot Dog & Holland & nd & 9.21 \\
\hline M3 & Plumrose Hot dogD & Germany & nd & 8.59 \\
\hline M4 & Zwan Beef + Olives Luncheon Meat & Holland & 0.2 & 23.14 \\
\hline M5 & Zwan Beef + Olives Luncheon Meat Mortadella & Holland & 3.2 & 5.29 \\
\hline M6 & Everyday Hot Dog & & 6.3 & 26.68 \\
\hline M7 & Zwan Turkey + Herbs & Holland & 8.8 & 21.66 \\
\hline M8 & Niers Beef Hot Dog & Holland & 18.4 & 10.4 \\
\hline M9 & Al Mouna Beef Luncheon Meat & Holland & 24 & 32.73 \\
\hline M10 & Tulipe Beef + Chicken Hot Dog & Denmark & 24.9 & 23.06 \\
\hline M11 & Al Taghziah Beef & Lebanon & 30.3 & 14.54 \\
\hline M12 & Turkey Saussages & & 36.7 & 4.77 \\
\hline Ch1 & Zwan Chicken Tandoori & Holland & nd & 4.77 \\
\hline Ch2 & Zwan Chicken + Paprika & Holland & nd & 4.2 \\
\hline Ch3 & Del Monte Chicken Luncheon Meat & Jordan & nd & 18.9 \\
\hline
\end{tabular}


Table 1: $\quad$ (Continued).

\begin{tabular}{|l|l|l|c|c|}
\hline Ch4 & Zwan Chicken + olives Luncheon Meat & Holland & nd & 11.15 \\
\hline Ch5 & Tanmia Chicken Luncheon Meat & Lebanon & nd & 9.06 \\
\hline Ch6 & Zwan Hot dog & Holland & nd & 55.81 \\
\hline Ch7 & Al Taghziah chicken Luncheon Meat Mortadella & Lebanon & nd & 32.76 \\
\hline Ch8 & Niers Chicken & Holland & nd & 4.19 \\
\hline Ch9 & Zwan Chicken Hot Dog In Glass & Holland & 1.4 & 2.53 \\
\hline Ch10 & Zwan Chicken Hot Dog & Holland & 3.6 & 1.75 \\
\hline Ch11 & Maxim's Chicken Luncheon Meat & Brazil & 8.1 & 2.47 \\
\hline Ch12 & Al Mouna Chicken & Holland & 11.5 & 9.95 \\
\hline Ch13 & Tulipe Chicken Luncheon Meat & Denmark & 11.6 & 0.69 \\
\hline Ch14 & Target Chicken Luncheon Meat & Holland & 12.1 & nd \\
\hline Ch15 & Maxim's Chicken Luncheon Meat & Brazil & 19.1 & 1.6 \\
\hline Ch16 & Maxim's Chicken Hot Dog & Brazil & 25.2 & 34.31 \\
\hline Ch17 & Maxim's Chicken Pate & Brazil & 26.5 & 2.66 \\
\hline Ch18 & Tulipe Chicken Hot Dog & Denmark & 38.2 & 3.3 \\
\hline Ch19 & Golden Fields & England & 46.8 & 38.78 \\
\hline Ch20 & Zwan Chicken & Holland & 47.7 & 4.24 \\
\hline Ch21 & Al Taghziah Chicken Luncheon meat & Lebanon & 816.1 & 36.21 \\
\hline Ch22 & Zwan Chicken Hot \& Spicy & Holland & nd & 4.91 \\
\hline D1 & Pate au Fois Gras & Lebanon & nd & 5.24 \\
\hline D2 & Pate au Fois Gras in Glass & Lebanon & nd & nd \\
\hline
\end{tabular}

$\mathrm{B}=$ beef, $\mathrm{P}=$ pork, $\mathrm{M}=$ mixed, $\mathrm{Ch}=$ chicken, $\mathrm{D}=$ duck, $\mathrm{nd}=$ nondetectable.

For the Processed (table 2), 91\% revealed $\mathrm{Pb}$ concentrations ranging from 0.245 to $61.3 \mu \mathrm{g} / \mathrm{kg}$, while $97 \%$ tested positive for the presence of $\mathrm{Cd}$ and ranged from 0.02 to $29.7 \mu \mathrm{g} / \mathrm{kg}$.

It was noted that concentrations of both metals were generally higher in canned meats (table 1) as opposed to the processed ones (table 2). This may be explained by the fact that leaching of both metals can occur from the can itself and into the product [24]. Moreover, and within each category, most samples showed slightly higher $\mathrm{Pb}$ levels than for $\mathrm{Cd}$. This may be explained due to the fact that $\mathrm{Pb}$ is more abundant than $\mathrm{Cd}$ thus leading to its role in increased accumulation and contamination. In general and when considering the general public, the data suggests that the safest products to consume are those containing non-detectable concentrations of both metals. Such products may include B1, 5, and 11, P1 and 2, and D2 (table 1).

It is well known in Lebanon that no regulations exist whatsoever to control the allowed amounts of toxic metals in food and their products. Therefore, it is necessary to use a certain guideline to figure out where we stand. According to the EU directive 466/2001 [1], which regulates the amounts of $\mathrm{Pb}$ and $\mathrm{Cd}$ in meat and their products, have set the maximum allowed levels (MAL) of both metals to be 100 and $50 \mu \mathrm{g} / \mathrm{kg}$, respectively. As for this study, it can be observed that various sample brands have markedly exceeded such levels where P14 $(413 \mu \mathrm{g} / \mathrm{kg})$ and Ch21 $(816.1 \mu \mathrm{g} / \mathrm{kg})$ have exceeded the MAL of Pb. As for the MAL of Cd, B2 $(75.76 \mu \mathrm{g} / \mathrm{kg})$, B10 $(65.75 \mu \mathrm{g} / \mathrm{kg})$, B24 $(89.27 \mu \mathrm{g} / \mathrm{kg}), \quad$ P4 $(74.53 \mu \mathrm{g} / \mathrm{kg}), \mathrm{P} 13(138.3 \mu \mathrm{g} / \mathrm{kg})$, and Ch6 $(55.81 \mu \mathrm{g} / \mathrm{kg})$ have all exceeded its allowed value (table 1 ).

In an attempt to compare our results with ones published internationally, it was very difficult to find published data that included canned meat products similar to the ones used in this study. From the 108 total sample brands studied 
Table 2: $\quad$ Lead and cadmium concentrations in processed meat brands. In the main text, sample brands are referred to by using their sample codes. Values are reported as mean concentrations in $\mu \mathrm{g} / \mathrm{kg}$ based on dry weight basis.

\begin{tabular}{|c|c|c|c|c|}
\hline $\begin{array}{l}\text { Sample } \\
\text { code }\end{array}$ & Brand Name & $\begin{array}{c}\text { Place of } \\
\text { Origin } \\
\end{array}$ & $\begin{array}{c}\mathbf{P b} \\
(\mu \mathrm{g} / \mathrm{kg})\end{array}$ & $\begin{array}{c}\text { Cd } \\
(\mu \mathrm{g} / \mathrm{kg})\end{array}$ \\
\hline $\mathrm{T} 1$ & Hohenrainer Turkey Grill Roast & Germany & nd & 4.75 \\
\hline $\mathrm{T} 2$ & Wawo Chicken Turkey & & 10.8 & 1.53 \\
\hline T3 & Hispania Deli Fume Turkey & Spain & 26.61 & 1.18 \\
\hline T4 & Hohenrainer Turkey Mortadella + Paprika & Germany & 14.6 & 4.64 \\
\hline T5 & La Piara Turkey & Spain & 25 & 2.54 \\
\hline T6 & Hohenrainer Mortadella Classic & Germany & 3.47 & 2.08 \\
\hline $\mathrm{T} 7$ & Voila Turkey Fume Turkey & Spain & 20.84 & 7.17 \\
\hline P1 & Buffet Premium & Spain & nd & 0.80 \\
\hline P2 & El Trineo Salami Pork & & 31.22 & nd \\
\hline P3 & Le 1er Choix(DD) Le Vrai Jambon Pork & UE & 39.24 & 3.35 \\
\hline $\mathrm{P} 4$ & Voila Pork & Spain & 49.7 & 0.75 \\
\hline P5 & Jambino Jambon & Bellgium & 2.96 & nd \\
\hline P6 & El Trineo Salami Poivra Pork & & 27.87 & 0.41 \\
\hline P7 & La Piara + Olives Pork & Spain & 43.9 & 1.36 \\
\hline P8 & Wenbo Peperoni & Denmark & 1.11 & 3.06 \\
\hline P9 & Monells Mortadella Pork & & 38.08 & 2.89 \\
\hline $\mathrm{P} 10$ & Leoncini Mortadella Pork & Italy & 11.6 & 0.25 \\
\hline P11 & Negroni Salami & Italy & 1.99 & 2.60 \\
\hline P12 & Citterio Mortadella Pork & & 14.68 & 0.75 \\
\hline $\mathrm{P} 13$ & Carsodo Salami + Pepper Pork & Girona & 4.91 & 0.49 \\
\hline P14 & Continental Jambon Pork & Bellgium & 10.98 & 5.10 \\
\hline $\mathrm{P} 15$ & Divina Mortadella Pork & Italy & 24.6 & 6.36 \\
\hline P16 & Jambino Jambon Fume & Bellgium & 0.245 & 0.56 \\
\hline P17 & Carsodo Salami & Girona & 1.04 & 0.38 \\
\hline P18 & Negroni Pork & Italy & 61.3 & 0.02 \\
\hline$(\mathrm{C}+\mathrm{T}) 1$ & La Piara Dinde & Spain & nd & 0.27 \\
\hline$(\mathrm{C}+\mathrm{T}) 2$ & La Piara Halal Turkey & Spain & 7.77 & 4.97 \\
\hline$(\mathrm{C}+\mathrm{T}) 3$ & La Piara Mortadella Chicken & Spain & 10.88 & 2.64 \\
\hline$(\mathrm{C}+\mathrm{T}) 4$ & La Piara Halal Chicken & Spain & 8.6 & 3.40 \\
\hline$(\mathrm{B}+\mathrm{C}) 1$ & La Piara Beef + olives + pepper $($ Beef + chicken) & Spain & 28.48 & 3.33 \\
\hline$(\mathrm{B}+\mathrm{C}) 2$ & La Piara Halal Beef (Beef + chicken) & Spain & 17.23 & 29.70 \\
\hline $\mathrm{P}+\mathrm{B}$ & Leoncini Mortadella Beef + Pork & Italy & 40.4 & 4.63 \\
\hline $\mathrm{P}+\mathrm{C}$ & Tello Mortadella + olives (Pork + Chicken) & Spain & 54.36 & 3.75 \\
\hline
\end{tabular}

$\mathrm{T}=$ turkey, $\mathrm{P}=$ pork, $\mathrm{C}+\mathrm{T}=$ chicken + turkey, $\mathrm{B}+\mathrm{C}=$ beef + chicken, $\mathrm{P}+\mathrm{B}=$ pork + beef, $\mathrm{P}+\mathrm{C}=$ pork + chicken, nd $=$ non-detectable.

in this work, we were able to compare only eight. Four of the processed meats (table 2) namely P3, 5, 14, and 16, which are ham were compared to six published studies between 1983 and 2002. Levels of Pb reported for P3 and 5 were comparable to Cervera [25], and Becerra et al. [26] respectively.

Whereas for Cd, P3, 14, and 16 were comparable to Dabeka and McKenzie [21], Cervera [25], and Karavoltsos et al. [22], respectively. For the rest of the ham samples, they were well below those reported by Catalá et al. [27], Cattaneo and Balzaretti [28], and Brito et al. [29].

Regarding the corned beef samples, four of the canned meats namely B1, 7, 9, and 13 were compared to Meah [30] and Onianwa et al. [23]. Our values in all four samples were much lower than those previously reported for both metals. In either case, neither the canned nor the processed meat brands discussed here (processed: P3, 5, 14, and 16, canned: B1, 7, 9, and 13) have exceeded the MALs 
of both metals. However, the concern arises from those that did exceed the allowed levels which were discussed earlier.

According to the TDS study made by Nasreddine et al. [3], the average weekly intake of $\mathrm{Pb}$ has reached $3.2 \%$ of the PTWI $(25 \mu \mathrm{g} / \mathrm{kg} \mathrm{bw})$, whereas the average weekly intake of $\mathrm{Cd}$ has reached $21.7 \%$ of its standard value $(7 \mu \mathrm{g} / \mathrm{kg}$ bw). Needless to mention, that such study did not account for any canned or processed meats nor can it be considered as a comprehensive total dietary study. However, it can serve as a guideline to calculate the additional intake that would be contributed from consuming canned or processed meats.

Lebanon is one of the countries that have recently been engaged in the process of performing Total Dietary Studies (TDS) as a reply to the EFSA/FAO/WHO questionnaire on national TDS approach [31], and yet still at the beginning in applying effectively and appropriately such studies. According to the European Environment and Health Information system, most European countries had an adult $\mathrm{Pb}$ intake levels ranging between $10-30 \%$ of the lead's PTWI and sometimes higher [32]. Given that Lebanon is a developing country in which no environmental or health regulations exist, nor does it have any food safety monitoring programs and regulations but yet its $\mathrm{Pb}$ intake is surprisingly much lower (3.2\%) than that of the European countries (10-30\%). It is not clear to why this great difference exists between the local TDS versus the EU TDS but this might be explained due to non-comprehensive nature of the TDS carried in Lebanon. In any case, the Lebanese TDS must be used since the study is area specific.

Knowing that the weekly intake of Pb reached 3.2\% of its PTWI $(25 \mu \mathrm{g} / \mathrm{kg})$, the remaining allowable intake $(24.2 \mu \mathrm{g} / \mathrm{kg}$ ) will not be reached by a $60-\mathrm{kg}$ adult when consuming one can (400g) or even two cans per week of any of the samples, which is still a reasonable amount to consume. However, if a 14-kg child consumes the same amounts, and without taking into account any TDS studies, the child can reach 93 and $186 \%$ of the PTWI when 1 or 2 cans of Ch21 or P14 (table 1) are consumed, respectively. This suggests that with a more comprehensive TDS, the intake level might increase thus making the matter worse for adults and even devastating for children.

Regarding cadmium, its intake through the food chain in the Lebanese TDS was found to be $21.7 \%$ of the PTWI $(7 \mu \mathrm{g} / \mathrm{kg}$ bw), which is also surprisingly lower than that of Europe (40-60\%) [32]. In that case, a 60-kg adult should have an additional allowable intake of $\mathrm{Pb}$ of $5.48 \mu \mathrm{g} / \mathrm{kg}$ in order to reach $100 \%$ of the PTWI. None of the samples analyzed were found to cause any risk when consumed. However, and similarly for children, consuming 800g of B24 or P13 per week can place them at risk. In both cases, whether for $\mathrm{Pb}$ or $\mathrm{Cd}$, intake levels must be regulated specifically for children in order to minimize exceeding the allowable levels.

Overall, the results of this study have suggested that is it safer to consume processed meats in comparison to canned ones since the processed products contained lower levels of both toxic metals. In addition, individuals should become aware of such results and should have the right to choose safer products so as to minimize exposure risk to such toxic elements. Consumption of products 
low in lead and cadmium whether in the canned or processed category do exist and can greatly minimize such exposures. Children were found to be most vulnerable and affected the most and therefore should minimize the consumption of such products. Whether being an adult or a child, the intake amount should be minimized as a basic rule so as to minimize the intake of such toxic metals since their presence has been confirmed. Last but not least, there is an urgent need to carry out comprehensive TDS studies specific for Lebanon only then, one can state with higher accuracy which products are safe and which are not.

\section{Conclusion}

The concentrations of lead and cadmium analyzed in this work revealed that two canned samples, (P14 and Ch21) have exceeded the MAL set for Pb by the European directive, whereas six canned samples (B2, 10, and 24, P4 and 13, and Ch6) have exceeded the MAL for Cd. This suggests that it is safer to consume processed meats as opposed to canned ones since the former showed lower concentrations of both metals and none have exceeded the MALs. Four of the total canned samples studied (P14, Ch21, B24, and P13) were found to contribute the highest intake when consumed by adults. Children were found to be markedly affected by such products where PTWIs were exceeded in their case.

Overall, this study suggests that the consumption of such products should be strictly controlled and minimized, especially for children. In light of this, researchers in the area as well as national health organizations should really engage in constant monitoring and evaluation of toxic metal levels in foodstuffs so as to establish national allowable values for the population and to strictly control any imported or even locally produced products since levels of toxic metals may change from time to time due to many factors.

\section{References}

[1] Dailos, G.-W. et al., Lead and Cadmium in meat products consumed by a Spanish population (Tenerife Island, Spain). Journal of Food Additives and Contaminants, 23(08), pp. 757-763, 2006.

[2] Al Othman, Z.A., Lead contamination in selected foods from Riyadh city market and estimation of the daily intake. Molecules, 15, pp. 7482-7497, 2010.

[3] Nasreddine, L. et al., Dietary exposure to essential and toxic trace elements from a Total diet study in an adult Lebanese urban population. Food and Chemical Toxicology, 48, pp. 1262-1269, 2010.

[4] Betsy, A. et al., Evolution of approaches in conducting total diet studies. Journal of Applied Toxicology, 32(10), pp. 765-776, 2012.

[5] Al-Chaarani, N., Measurement of levels of heavy metal contamination in vegetables grown and sold in selected areas in Lebanon. Jordan Journal of Chemistry, 4(3), pp. 305-317, 2009. 
[6] Obeid, P.J. et al., Determination and assessment of total mercury levels in local, frozen and canned fish in Lebanon. Journal of Environmental Sciences, 23(9), pp. 1-6, 2011.

[7] Khan, F. U. et al., Health hazard of trace elements in the human body. Science Technology and Development, 9, pp. 30-34, 1990.

[8] Khan, K. H. et al., Ground water pollution by heavy metals. Science Technology and Development, 14, pp. 1-5, 1996.

[9] World Health Organisation (WHO), Lead. In: Safety evaluation of certain food additives and contaminants. Fifty-third meeting of the Joint FAO/WHO Expert Committee on Food Additives (JECFA), Geneva: WHO Food Additives Series, 44, pp. 273-312, 2000.

[10] World Health Organisation (WHO), Cadmium. In: Safety evaluation of certain food additives and contaminants. Fifty-fifth meeting of the Joint FAO/WHO Expert Committee on Food Additives (JECFA), Geneva: WHO Food Additives Series, 46, pp. 247-305, 2001.

[11] Halliwell, D., Turoczy, N., and Stagnitti, F., Lead concentrations in Eucalyptus sp. in a small coastal town. Bulletin of Environmental Contamination and Toxicology, 65(5), pp. 583-590, 2000.

[12] National Toxicology Program, Department of Health and Human Services Report on Carcinogens, Twelfth Edition Cadmium and Cadmium Compounds CAS No.7440-43-9 (Cadmium), 2011. http://ntp.niehs.nih.gov/ntp/roc/ twelfth/profiles/Cadmium.pdf

[13] Rubio, C. et al., Lead dietary intake in a Spanish population (Canary Islands). Journal of Agricultural and Food Chemistry, 53(16), pp. 65436549, 2005.

[14] Rubio, C. et al., Cadmium dietary intake in the Canary Islands, Spain. Environmental Research, 100(1), pp. 123-129, 2006.

[15] Sabir, S.M., Khan, S.W. and Hayat, I., Effect of environmental pollution on quality of meat in district Bagh, Azad Kashmir. Pakistan Journal of Nutrition, 2(2), pp. 98-101, 2003.

[16] Rahimi, E. and Rokni, N., Measurement of cadmium residues in muscle, liver and kidney of cattle slaughtered in Isfahan abattoir using grafite furnace atomic absorption spectrometry (GFAAS): a preliminary study. Iranian Journal of Veterinary Research, 9(2), pp. 174-177, 2008.

[17] López, A.M. et al., Toxic and trace elements in liver, kidney and meat from cattle slaughtered in Galicia (NW Spain). Food Additives and Contaminants, 17(6), pp. 447-457, 2000.

[18] Tahvonen, R. and Kumpulainen, J., Lead and cadmium contents in pork, beef and chicken, and in pig and cow liver in Finland during 1991. Food Additives and Contaminants, 11(4), pp. 415-426, 1994.

[19] Larsen, E.H., Monitoring the content and intake of trace elements from food in Denmark. Food Additives and Contaminants, 19(1), pp. 33-46, 2002.

[20] López, A.M. et al., Cadmium and lead accumulation in cattle in NW Spain. Veterinary and Human Toxicology, 45(3), pp. 128-130, 2003. 
[21] Dabeka, R.W. and McKenzie, A., Total diet study of lead and cadmium in food composites: preliminary investigations. Journal of the Association of Official Analytical Chemists, 75(3), pp. 386-394, 1992.

[22] Karavoltsos, S. et al., Cadmium content in foodstuffs from Greek market. Food Additives and Contaminants, 19(10), pp. 954-962, 2002.

[23] Onianwa, P.C. et al., Cadmium and nickel composition of Nigerian foods. Journal of Food Composition and Analysis, 13(6), pp. 961-969, 2000.

[24] Food Safety: Theory and Practice, Jones \& Bartlett Publishers, 2011. http://books.google.com.lb/books?id=CzkmOO0CPaUC\&dq=leaching+of + lead+and+cadmium+from+cans+to+canned+food\& source=gbs_navlinks_s

[25] Cervera, M.L., Modificaciones del cotenido en cadmio, cobre, plomo y cinc en los procesos de elaboración de jamón cocido y pasta de hígado. Revista de Agroquímica y Tecnología de los Alimentos, 28(2), pp. 233-240, 1988.

[26] Becerra, G., Burguera, J.L., and Buguera, M., Determination of lead and cadmium in foods samples by flow-injection atomic absorption spectrometry, Química Analítica, 6, pp. 52-59, 1987.

[27] Catalá, R., Montoro, E., and Ibáñez, N., Contaminación por metales pesados de los productos cárnicos. Revista de Agroquímica y Tecnología de los Alimentos, 23(2), pp. 202-216, 1983.

[28] Cattaneo, P. and Balzaretti, C., 1984. Livelli attuallidi piombo e cadmio negli alimenti. Industrie Alimentari, 23, pp. 771-780, 1984.

[29] Brito, G. et al., Levels of metals in canned meat products: Intermetallic correlations. Bulletin of Environmental Contamination and Toxicology 44(2), pp. 309-316, 1990.

[30] Meah, M.N., Lead and tin in canned foods: results of the UK survey 19831987. Food Additives and Contaminants, 8(4), pp. 485-496, 1991.

[31] State of the art on total diet studies based on the replies to the EFSA/FAO/WHO questionnaire on national total diet study approaches. European Food Safety Authority (EFSA), Food and Agriculture Organization of the United Nations (FAO), \& World Health Organization (WHO), 2011. http://www.efsa.europa.eu/en/supporting/doc/206e.pdf

[32] Exposure of children to potentially hazardous chemicals in food. European Environment and Health Information System (ENHIS), 2009. http://www.euro.who.int/_data/assets/pdf_file/0004/97042/4.4.-Exposureof-children-to-chemical-hazards-in-food-EDITED_layouted.pdf 